Article

\title{
Optimized Particle Swarm Optimization Algorithm for the Realization of an Enhanced Energy-Aware Location-Aided Routing Protocol in MANET
}

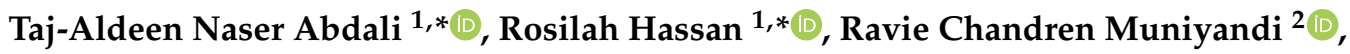 \\ Azana Hafizah Mohd Aman ${ }^{1}\left(\mathbb{D}\right.$, Quang Ngoc Nguyen $\left.{ }^{3}{ }^{(}\right)$and Ahmed Salih Al-Khaleefa ${ }^{1,4}$ \\ 1 Centre for Cyber Security, Faculty of Information Science and Technology (FTSM), Universiti Kebangsaan \\ Malaysia (UKM), Bangi 43600, Malaysia; azana@ukm.edu.my (A.H.M.A.); \\ ahmed.salih89@siswa.ukm.edu.my (A.S.A.-K.) \\ 2 Research Center for Cyber Security, Faculty of Information Science and Technology, Universiti Kebangsaan \\ Malaysia (UKM), Bangi 43600, Malaysia; ravie@ukm.edu.my \\ 3 Department of Communications and Computer Engineering, Faculty of Science and Engineering, \\ Waseda University, Tokyo 169-8050, Japan; quang.nguyen@aoni.waseda.jp \\ 4 Department of Computer Techniques Engineering, Faculty of Information Technology, Imam Jafar Al-Sadiq \\ University, Maysan 10011, Iraq \\ * Correspondence: tag_naser2002@yahoo.com (T.-A.N.A.); rosilah@ukm.edu.my (R.H.)
}

Received: 5 October 2020; Accepted: 8 November 2020; Published: 15 November 2020

\begin{abstract}
Mobile Ad-hoc Network (MANETs) is a wireless network topology with mobile network nodes and movable communication routes. In addition, the network nodes in MANETs are free to either join or leave the network. Typically, routing in MANETs is multi-hop because of the limited communication range of nodes. Then, routing protocols have been developed for MANETs. Among them, energy-aware location-aided routing (EALAR) is an efficient reactive MANET routing protocol that has been recently obtained by integrating particle swarm optimization (PSO) with mutation operation into the conventional LAR protocol. However, the mutation operation (nonuniform) used in EALAR has some drawbacks, which make EALAR provide insufficient exploration, exploitation, and diversity of solutions. Therefore, this study aims to propose to apply the Optimized PSO (OPSO) via adopting a mutation operation (uniform) instead of nonuniform. The OPSO is integrated into the LAR protocol to enhance all critical performance metrics, including packet delivery ratio, energy consumption, overhead, and end-to-end delay.
\end{abstract}

Keywords: mobile ad hoc network; location-aided routing protocol; particle swarm optimization

\section{Introduction}

Wireless networks can be categorized into two types: infrastructure and infrastructure-less networks [1]. In infrastructure wireless communication networks, a mobile ad hoc network (MANET) is a wireless network topology with mobile network nodes and movable communication routes [2]. In other words, MANETs realize networks and have active topology because of their node mobility. MANETs have homogeneous and heterogeneous types [3]. In MANETs, the routing protocol is critical because of various limitations in the network and node environment [4]. Research on MANETs is limited by their flexible dynamic architecture, quality of service (QoS), and scarce resources [5]. Each node in self-organized or self-configured MANETs, such as civilian MANETs, acts as an independent node and may not share goals with any other node(s) [6]. By contrast, an infrastructure-less or decentralized ad hoc wireless network does not rely on any network infrastructure, and a mobile node operates as an end node or router while communicating with others [7]. MANETs can be classified into proactive, 
reactive, and hybrid [8]. We present this category in Figure 1. The proactive MANET protocol implements a group of protocols to update the information table in the node periodically. The reactive or on-demand approach updates the node with information upon request [9]. Finally, the hybrid approach is a combination of proactive and reactive protocols $[10,11]$.

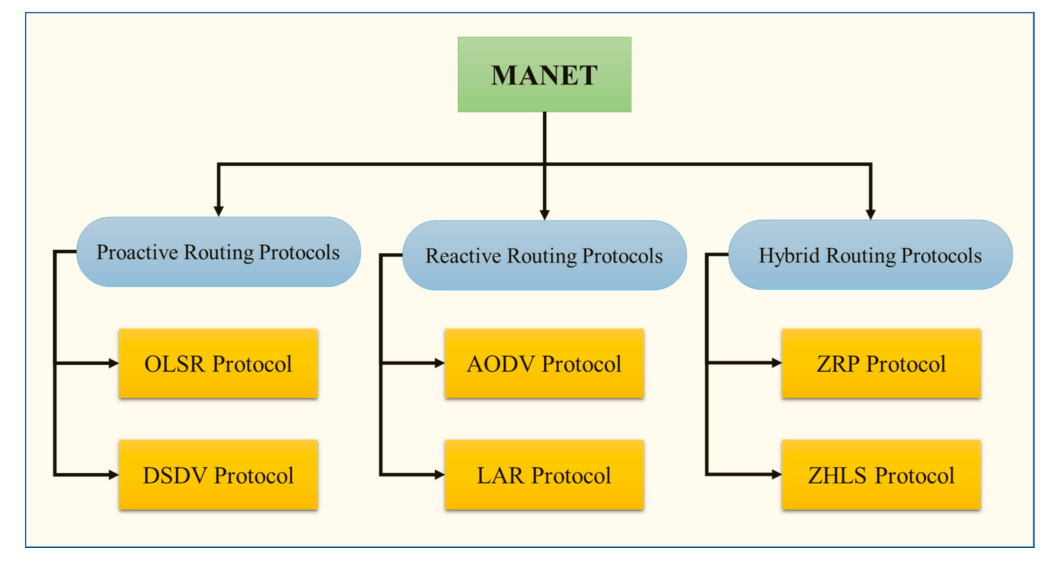

Figure 1. Mobile Ad-hoc Network (MANET) categories.

A reactive routing protocol in MANET is LAR [12,13]. It utilizes the geographical data for locating the area and discovering an efficient route to reach the target, i.e., the request zone. The source node estimates the round area (expected zone), whereas the destination is likely to respond in time. In specific, the requesting node sends the flooding routing requests to all the network nodes, and the ones currently located in a request zone would forward the data. The position and the size of the round zone are selected depending on the prior requesting pattern information. The requesting time corresponds to the destination, average speed, and prior location. The requested zone is a small area that includes the expected zone and the source. Many studies have specified the optimal size of the requested zone to forward subsequent requests when a node presented in the requested zone (instead of the outside nodes) receives a Route Request Packet (RREQ). Table 1 presents a comparison between the different categories of routing protocols in MANETs in the aspect of some important features of the LAR, Ad hoc On-demand Distance Vector (AODV), and Optimal Link State Routing (OLSR) protocols.

Table 1. Comparison among Location-Aided Routing (LAR), Ad hoc On-demand Distance Vector (AODV), and Optimal Link State Routing (OLSR) protocols.

\begin{tabular}{|c|c|c|c|c|}
\hline Features & LAR & AODV & OLSR & References \\
\hline Implementation complexity & Low & Low & Low & [14] \\
\hline Number of hops & Custom & Unlimited & Unlimited & [14] \\
\hline GPS & $\checkmark$ & $x$ & $x$ & [15] \\
\hline Energy consumption & Low & Low & High & [16] \\
\hline Connectivity range & High & Small & Medium & [17] \\
\hline RREQ & Flooding & Multipoint relays & Routes on demand & [18] \\
\hline Medium Access Protocol & IEEE 802.11 & IEEE 802.11 & IEEE 802.11 & [15] \\
\hline
\end{tabular}

The LAR protocol suffers from many issues, such as the overhead, end-to-end delay (E2E delay), and difficulty in handling void zones [19], which occur because of the flooding of RREQs in the LAR protocol [20].

The LAR protocol uses a GPS system to determine the node position information. On the basis of a common solution, GPS solves location issues by using position information. However, GPS-dependent location is unreliable because of vertical orientation and the prevalent vertical motion, restricting the LAR protocol to low speed networks. However, different optimization strategies can improve the efficiency of LAR [21]. Therefore, several studies have focused on the concept of energy with different 
methodologies. One popular method involves using metaheuristic approaches, such as genetic algorithm [22] and particle swarm optimization (PSO) [23]. This paper focuses on data transfer between nodes of the actual MANET, which absorbs the battery level in the nodes and guarantees early shutdown of the node for the lifetime of the nodes in the network, which influences connectivity and maintains packet transmission to the nodes. Therefore, the protocol must be carefully modified to use the route and to transfer data with a high level of energy consideration by using Optimized PSO (OPSO) [24] and adapting [23,25] to be a benchmark for evaluating the performance of the proposed approach.

\section{Energy Efficiency (EE) Studies in LAR of Ad Hoc Networks}

The LAR protocol is an interesting area for researchers. Several studies have tackled the limitation of the LAR protocol with different categories. This section presents the summaries of related studies with the LAR protocol and the related study of the PSO algorithm. Several efforts have been exerted to diminish the amount of power wastage. For instance, an energy-efficient scheme adopted by the AODV as a new model using the LAR protocol to reduce energy consumption aids the routing corresponding to the location. This study proposes a new location-based energy-efficient scheme with the AODV protocol. The main disadvantage of this new development is that the network nodes do not record their energy consumption, resulting in high energy usage [26].

Researchers on MANETs aimed to reduce the energy consumption of the node. For instance, Ref. [27] proposed a model to enhance the performance of the MANET protocol to ensure efficient performance by using a LAR-1 model that can reduce energy consumption by extending the network lifetime in a dynamic network. The antennas have some dismissed route discovery through untargeted flooding of the route request packets outside the coverage area between the source node and the destination node. This study has a concern about the flooding of the LAR protocol in the request zone. Adding adaptive LAR with directional antenna could reduce the propagation of the redundant route using restricted flooding antennae and directional antennae [20].

Some studies have focused on another aspect given its importance can contribute to MANET protocols the overhead during the limitation of the network effects to increase the number of packets to the sender (request node). Hence, the continuation by sending the packet minimizes the battery life until shutdown. Ref. [28] has suggested a new location-aided zone routing protocol (ZRP) to elucidate the mechanism used to seek the route from the source node to the destination node with high probability. However, this method creates many idle paths in the network and high overhead cost. Therefore, this study proposed a model using geographical information based on ZRP to minimize the discovered area and decrease the number of sent packets, thereby diminishing the overhead. In the same content, Khushboo [29] developed an energy-efficient LAR protocol (PA-LAR) that uses linear regression and curve intersection point area to minimize the request zone and organize node behavior on the basis of the battery level.

The PA-LAR protocol determines the dependent node to save the energy to improve network survival along with the routing capability based on the curve and location for the LAR and AODV protocols. Zhang et al. [30] established the cost-efficient QoS routing protocol (CEQRP). The rules of this protocol consist of two aspects. First is the path_bandwith from the node of source to the node of destination. Second is that the routing_cost requirement to select the middle node (host) should be the lowest possible.

For proactive routing protocols, Ref. [31] proposed the quantum genetic-based OLSR protocol (QG-OLSR). This study considered two aspects in reducing network topology consumption and the time delay for E2E delay packet transmission between nodes by using the newly augmented Q-Learning algorithm and combining with OLSR to optimize the selection of multipoint relay sets. Previous studies aimed to enhance QoS to maintain the optimal performance of the MANET environment. Therefore, this study followed previous procedures to develop the QoS in the energy part. Table 1 provides a summary of the previous studies and the points of differences. 
Nature-inspired algorithms can be used to solve various real-world optimization problems; thus, such algorithms have continued to receive research attention in recent decades. In addition, optimization problems are faced with the problem of search space complexity. Nature-inspired algorithms have two basic forms: evolutionary algorithms (EA) and swarm-based algorithms. EAs are inspired by the natural concept of evolution [32]. They are a subset of evolutionary computations, a generic metaheuristic (population-based) that is contrived to solve problems with high complexity [33], such as nondeterministic polynomial-time (NP-hard) problems [34]. Several studies use metaheuristic to solve the problems of routing protocols in MANETs.

This algorithm can be used to solve problems that require the systematic enumeration of all potential candidates for reaching the global optimal can also be solved by using this algorithm [35]. Metaheuristic algorithms are inspired by nature as an efficient way to deal with various complex searching and optimization problems in different fields. PSO is a popular and state-of-the-art algorithm proposed by [36]. It is inspired by the behavior of bird flocks; in particular, PSO applied to MANETs appears like a difficult mechanism, but it has direct calculations to find the exact route leading to the destination. The procedure of PSO depends on the swarm that is taking the same behavior as the nodes. During the searching procedure in the solution space, PSO runs through some iterations that are determined with parameters to find the best route, which is near the destination node to send the data at a low cost. The node in the network of MANETs can act as the sender, receiver, and route at the same time. In addition, it can change its position from place to other [37]. Some studies have tackled the limitation of MANETs [38] and proposed an Extensible PSO (EPSO) model to find the reliable routing path in accordance with some rules. The battery level should have enough energy to forward the packet and the data continuously. EPSO starts operating by searching the possible routes for the sender and receiver nodes in the network and checking several routes to enable EPSO. Improving the possible route this step prepared allows the algorithm to choose the route set to revive the load-controlling path and increases the network lifetime and efficiency.

In [39], the Cuckoo Search (CS) algorithm was implemented by enhancing the conventional CS technique using the reactive routing Cuckoo Search Optimization AODV (CSOAODV) protocol. This study aimed to ensure the QoS path by calculating the best fitness value because whether or not the short path can be the optimal Route Replay (RRPLY) packet of the AODV protocol has no guarantee. The model modifies the default setup of the AODV protocol to calculate the best path by the number of hubs from the source to the destination. The lowest number of hubs is considered as the path, whereas CSOAODV considers best fitness as value computation. The best fitness value is determined with three criteria: calculated residual energy, hop count, and routing load.

In the same protocol, Ref. [32] used the shuffled frog-leaping algorithm with the AODV protocol and the proposed model named frog-leaping algorithm-based ad hoc on-demand distance vector (SEAL-AODV). SEAL computes the optimal path for AODV based on the following criteria: residual energy, hop count, and routing load of [39] but different algorithms. Shubhajeet Chatterjee [40] proposed a model to enhance the performance of dynamic source routing (DSR) using the ant colony optimization algorithm, to achieve high packet delivery ratio, low E2E delay, and low overhead cost when the source node wants to send RREQ. All previous achievements ensure the energy consumption will be minimized in the $=$ MANETs.

In the enhanced-ant-DSR algorithm, the source node is required to send a packet for the destination first step to check the cache. When no routes are well known, the source node broadcasts the route request control packets locally called by (Req.Ant packets) to find a route. When the RREQ (Req.Ant packets) reach the destination node, its forward route reply control packet contains route information of the source node through the same route. The conclusion of the previous studies presents the aim and the directions of some interested researchers in MANETs. The majority focused on the reactive part of MANETs, and the energy part is the most important field. Table 2 summarizes the related studies. Therefore, this study focuses on the reactive part generally and LAR protocol particularly to enhance the performance and minimize energy consumption. 
Table 2. Summary of related work in MANET.

\begin{tabular}{|c|c|c|c|c|c|}
\hline Author's & Protocol & Methodology/Disadvantages & Proactive & Reactive & Hybrid \\
\hline [26] & AODV & $\begin{array}{l}\text { Method: This study enhanced the performance of AODV based on the location information of the } \\
\text { LAR protocol to minimize energy consumption. } \\
\text { Disadvantage: LAR protocol default setup lacking with redundant of flooding in the request zone. } \\
\text { This might increase the overhead and E2Edealy. }\end{array}$ & & $\checkmark$ & \\
\hline [27] & LAR-1 & $\begin{array}{l}\text { Method: LAR-1 developed with the association of the Power-Aware Dynamic Source Routing } \\
\text { (PADSR) energy model. The concertation of the energy model was truly affected by the MANET } \\
\text { network. } \\
\text { Disadvantage: referring to the simulation parameters in the environment if being increased and the } \\
\text { number of nodes is the same. In this case, the distance between the nodes increased and the } \\
\text { possibility to drop the packet is high when the node shutdown. }\end{array}$ & & $\checkmark$ & \\
\hline [20] & ALAR-DA & $\begin{array}{l}\text { Method: This contribution of this study by adding (ALAR-DA) to achieve and reduce the redundant } \\
\text { route discovery propagations by using both a scheme of restricted flooding and directional antennas. } \\
\text { Disadvantage: assuming we have a smaller number of nodes in the simulation environment, the } \\
\text { complexity to deliver packet into the destination node. }\end{array}$ & & $\checkmark$ & \\
\hline$[28]$ & LAZARP & $\begin{array}{l}\text { Method: A new model, called Location-Aided Zone Routing Protocol (LAZRP), studies the } \\
\text { mechanism that is used to seek for the route from the source node to the destination node with high } \\
\text { probability. This method bail to create many idle paths in the network and cost the overhead. } \\
\text { Disadvantage: there's no concern about energy consumption. }\end{array}$ & & & $\checkmark$ \\
\hline [29] & PA-LAR & $\begin{array}{c}\text { Method: use Linear Regression and curve intersection point area to minimize the request zone and } \\
\text { organize node behavior on the base of the battery level. } \\
\text { Disadvantage: Does not consider energy for route computation. }\end{array}$ & & $\checkmark$ & \\
\hline [30] & CEQRP & $\begin{array}{l}\text { Method: Consider two aspects: firstly, the path_bandwith from the source node to the destination } \\
\text { node. secondly, the routing_cost requirements to select the middle node (host) should be chosen the } \\
\text { lowest cost as small as possible. } \\
\text { Disadvantage: High probability of route } \\
\text { failure due to the use of source route concept }\end{array}$ & & & $\checkmark$ \\
\hline$[31]$ & QG-OLSR & $\begin{array}{l}\text { Method: Reduce the consumption of the network topology control and reduce the time delay for } \\
\text { E2E delay packet transmission between the nodes by using new augmented Q-Learning algorithm. } \\
\text { Disadvantage: Nodes do not exchange } \\
\text { their energy states information. }\end{array}$ & $\checkmark$ & & \\
\hline
\end{tabular}


Table 2. Cont.

\begin{tabular}{|c|c|c|c|c|c|}
\hline Author's & Protocol & Methodology/Disadvantages & Proactive & Reactive & Hybrid \\
\hline$[38]$ & EPSO & $\begin{array}{l}\text { Method: Find the reliable routing path and this will be following some rules to choose the path. The } \\
\text { battery level should have enough energy to forward the packet and the data continuously. } \\
\text { Disadvantage: Ignores movement } \\
\text { Direction. }\end{array}$ & & & \\
\hline [39] & CSOAODV & $\begin{array}{l}\text { Method: Ensure the QoS path by calculating the best fitness value because there is no guaranteed } \\
\text { proof the short path can be optimal Route Replay (RRPLY) packet of AODV protocol. } \\
\text { Disadvantage: Higher chance of collisions when the node has a longer transmission range }\end{array}$ & & $\checkmark$ & \\
\hline [32] & SEAL-AODV & $\begin{array}{c}\text { Method: Compute the optimal path for AODV based on numerous criteria as follows residual } \\
\text { energy, hop count, and routing load. } \\
\begin{array}{c}\text { Disadvantage: this might increase the overhead for the network and increased the number of } \\
\text { dropped packets. }\end{array}\end{array}$ & & $\checkmark$ & \\
\hline [40] & E-Ant-DSR & $\begin{array}{l}\text { Method: Using DSR with the ACO algorithm, to achieve the high packet delivery ratio, low E2E } \\
\text { delay, and the lowest overhead when the source node wants to send RREQ. } \\
\text { Disadvantage: there is no consideration for energy consumption. }\end{array}$ & & $\checkmark$ & \\
\hline
\end{tabular}




\section{Materials and Methods}

This section consists of four main subsections. Section 3.1 introduces the PSO algorithm and the procedure of general steps. The LAR protocol framework and its principles are presented in Section 3.2, the RREQ mechanism is explained in Section 3.3, and the optimization mechanism is elucidated in Section 3.4.

\subsection{Particle Swarm Optimization Algorithm (PSO)}

The PSO algorithm was presented for the first time by Kennedy and Eberhart [36] as a computational procedure for optimizing problems iteratively; it was inspired by the social life style of birds within a flock, with each bird considered as a particle within the hyperdimensional search space. The position of the particles in the search space is flexible and changeable following the social-psychological tendency depending on the individuals. The particle mobility within the swarm is affected by two aspect knowledge or swarm experiences. The consequence of designing social behavior is that how the swarms return to the previous successful regions in the solution space. The velocity of each particle termed (v) and the position (x) of the particles are solved using the following formula:

$$
\begin{gathered}
v_{i j}(t+1)=w_{i j}+C_{1} r_{1}\left(p B_{i j}(t)-x_{i j}(t)\right)+C_{2} r_{2}\left(g B_{i j}(t)-x_{i j}(t)\right) ; \\
x_{i j}(t+1)=x_{i j}(t)+v_{i j}(t+1),
\end{gathered}
$$

where $v_{i j}(t+1)$ denotes the velocity of particle $i$ at iteration $j$, where $x_{i j}(t+1)$ is the position of particle $i$ at iteration $j$, and $t$ denotes the number of iterations. Moreover, $w_{-} i j$ is the inertia weight to be hired for controlling the influence of the previous record of velocity. $C_{1}$ is the awareness learning factor, $C_{2}$ is the gregarious learning factor, and $r_{1}, r_{2}$ is the random number for solution space between $[0,1]$ for controlled the stored info ability. In other words, to maintain the component velocity $(v)$ determined with range $\left[-v_{\max }, v_{\max }\right]$ to track or delete the immoderate pace. The PSO algorithm reaches the optimal generation or the optimal position of the particle, which is part of the swarm. In this stage, $i$ is not improved if the number of generations is further increased. Hence, PSO proves the effectivity and superiority to solve high-complexity optimization problems.

\subsection{Location-Aided Routing Protocol (LAR)}

LAR was proposed by Young-Bae Ko and Nitin H. Vaidya [12,41] as one of the first routing protocols that consider location information during routing in MANETs. The LAR was based on the source node $(S)$ and relies on the location information of the destination node $(D)$. The expected zone in this operation has been estimated as the destination area for $D$. The expected zone is illustrated in Figure 2, with $t_{1}$ being the $S$ velocity of $D$ at $L_{0}\left(X_{0}, Y_{0}\right)$ within time $t_{0}$ while $V$ is the mean velocity of $D$. Thus, the radius, $V\left(t_{1}-t_{0}\right)$ is the area in the mid-point of $L_{0}\left(X_{0}, Y_{0}\right)$ for the expected zone.

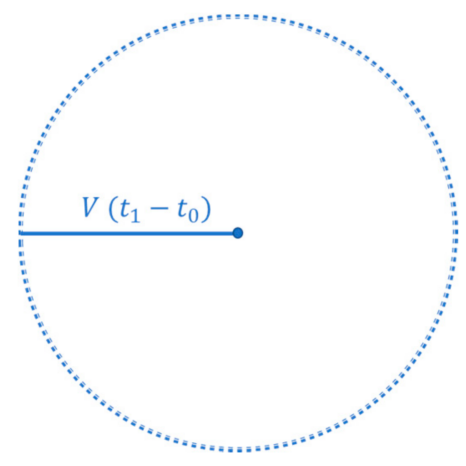

Figure 2. Expected zone in LAR protocol. 
LAR floods the network with RREQ, making sure the packets are neither reaching the $D$ node nor increasing the rate of packets forwarding. For LAR to work properly, the nodes must be aware of the nodes within the request zone; hence, the nodes can either keep forwarding the flooded packet or drop it. In this study, two methods of detecting the existence of nodes within the request zone were proposed. The first method, as shown in Scheme 1, requires the transmitter to propagate an RREQ that has rectangle coordinates with the request zone; here, the route request is ignored by the nodes outside the rectangle (in Scheme 1) but forwards it if it is inside the request zone Once the route request has reached the destination, it replies with the route reply message and this procedure called Scheme 1.

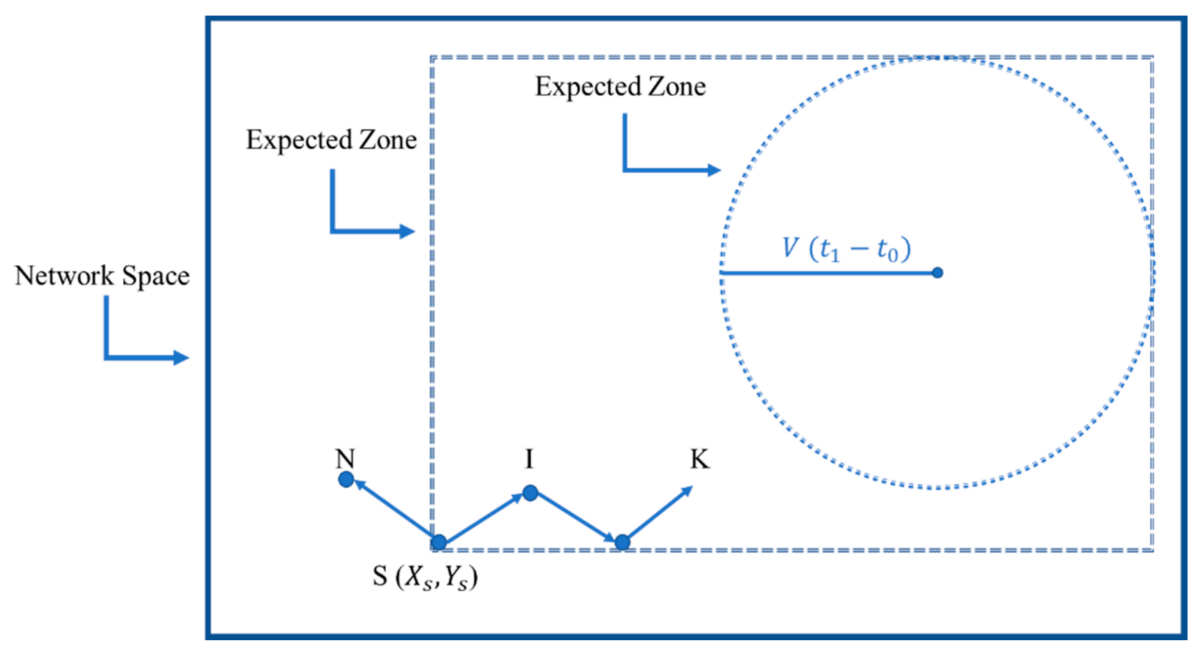

Scheme 1. First LAR protocol Scheme 1 [12].

Scheme 2 uses the distance from the previous location of $D$ and considers it as a parameter to locate a request zone. Hence, if any middle node $J$ receives the RREQ packet it is forwarding if $J$ near the previous destination location node $I$ transmitting the request packet to $J$. In other words, the implied request zone of scheme 2 is suitable if the RREQ when reproducing the number of nodes presented in Scheme 2.

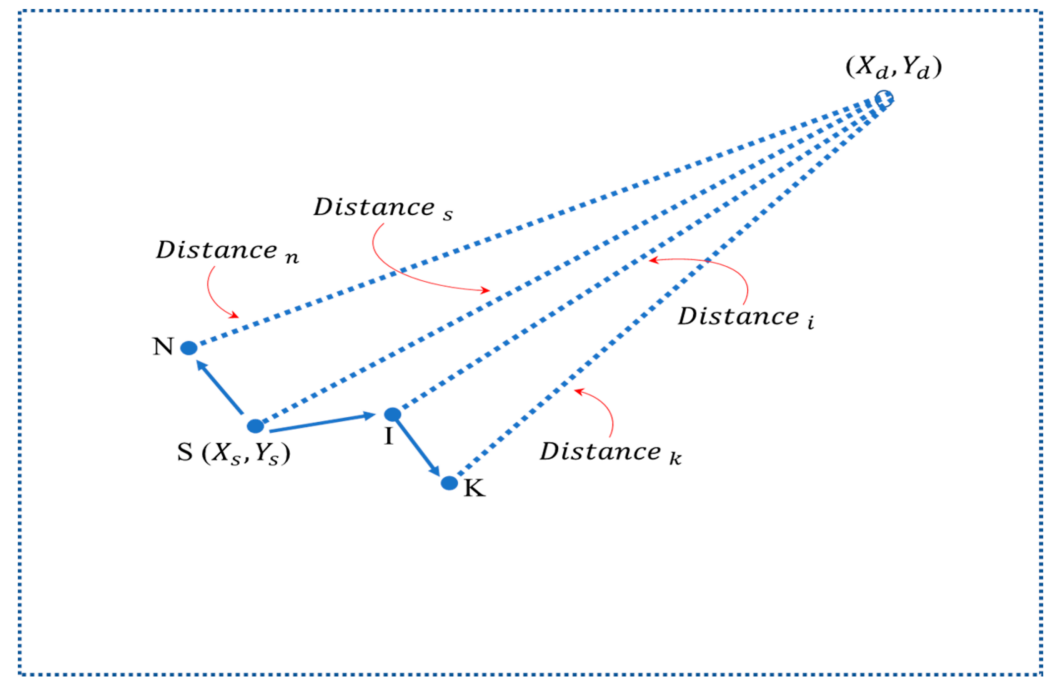

Scheme 2. LAR protocol scheme 2 [12].

Optimized Particle Swarm Optimization Algorithm-Location Aided-Routing Protocol (OPSO-LAR). 
The proposed model of the LAR protocol is termed OPSO-LAR, which adapts the optimized PSO algorithm. The optimization algorithm aids in searching the space for the individual solutions to be fed into the LAR simulator for the generation of network measures. Then, the fitness values of the generated solution are calculated after feeding the solutions into the objective function. Figure 3 presents the procedure inside the network of OPSO-LAR. The source node (blue) generates the data packet and broadcasts the RREQ packet to find a route toward the destination. The destination node (the yellow node) is the node to which the data packet must be delivered. The intermediate node (the green nodes) holds the RREQ packet and has to broadcast it to its neighbors. The baseline is the vector that connects the source and destination nodes. Distance ( $x$. destination) is the Euclidian distance between the node $x$ (intermediate node) and the destination node. Angle $x$ is the angle between the baseline and the vector that connects the source node and the node $x$ to the destination. Furthermore, the current position of each node is known as the network that maintains an updated record of the position and energies of each node and its neighbors. The position of the destination node is the source node; hence, this position will be added to the position of the source node, and the position of the source node will be added to the RREQ packet.

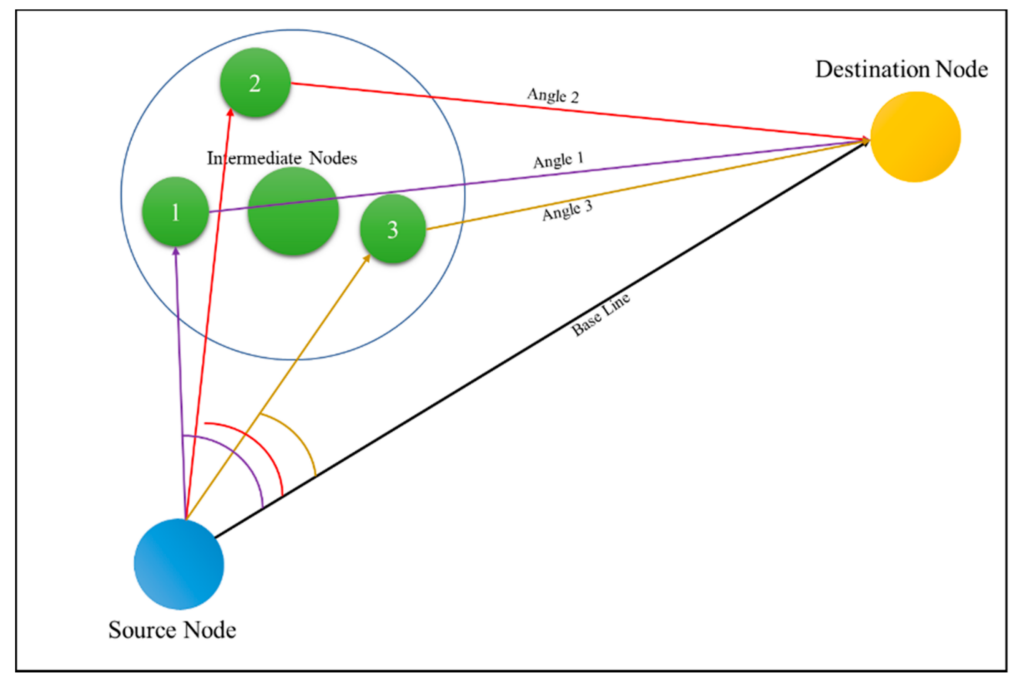

Figure 3. Optimized Particle Swarm Optimization- Location-Aided Routing (OPSO-LAR) mechanism.

This information guarantees that each node holding the RREQ packet in the network knows the positions of the source and destination nodes. Moreover, the intermediate nodes are required to meet some conditions, including the angle, distance, and energy level, to be calculated in the criterion function using the following formula:

$$
\begin{aligned}
& \text { Criterion Function }=\mathrm{f}_{\text {node }}=\mathrm{w}_{1} * \text { Angle (node) }+\mathrm{w}_{2} * \\
& \text { Dis (node } \mathrm{x} \text {. destination) }+\mathrm{w}_{3} * \text { Energy Consumption (node), }
\end{aligned}
$$

where

$$
\begin{gathered}
\text { Angle (node) }=\frac{\text { Angle (node) }}{180} \in[0.1] \\
\text { Distance(node x. destination) }=\frac{\text { Dis (node x. destination) }}{\text { length of enviroment' s diagonal }} \in[0,1] \\
\text { Energy Conumption (node) }=\frac{\text { Initial Battery (node) - Current Battery (node) }}{\text { Initial Battery (node) }} \in[0,1]
\end{gathered}
$$


$\mathrm{w}_{1}, \mathrm{w}_{2}$, and $\mathrm{w}_{3} \in\left[\begin{array}{ll}0 & 1]\end{array}\right.$ represent the weighting factors of the variables used in the objective function and play a role in the effectiveness of the request zone. After calculating the three conditions, the flooding ratio (FR) decides how many nodes forward the RREQ.

\subsection{RREQ Compare Mechanism}

Assuming we have three intermediate nodes $(\mathrm{A}, \mathrm{B}, \mathrm{C})$ waiting to forward the RREQ to the next node, each node is required to present three conditions, namely, the angle, distance, and energy level to be calculated by criterion function. If node $\mathrm{A}$ has a lower angle, distance, and highest energy level and $A$ is greater than $B$ and $C$, then the nodes will sort in ascending order. The value of $A$ considers as a threshold. If the node $n$ is greater than $\mathrm{A}$, the threshold will be terminated and replaced with node $n$. Algorithm 1 presents a comparison of RREQ.

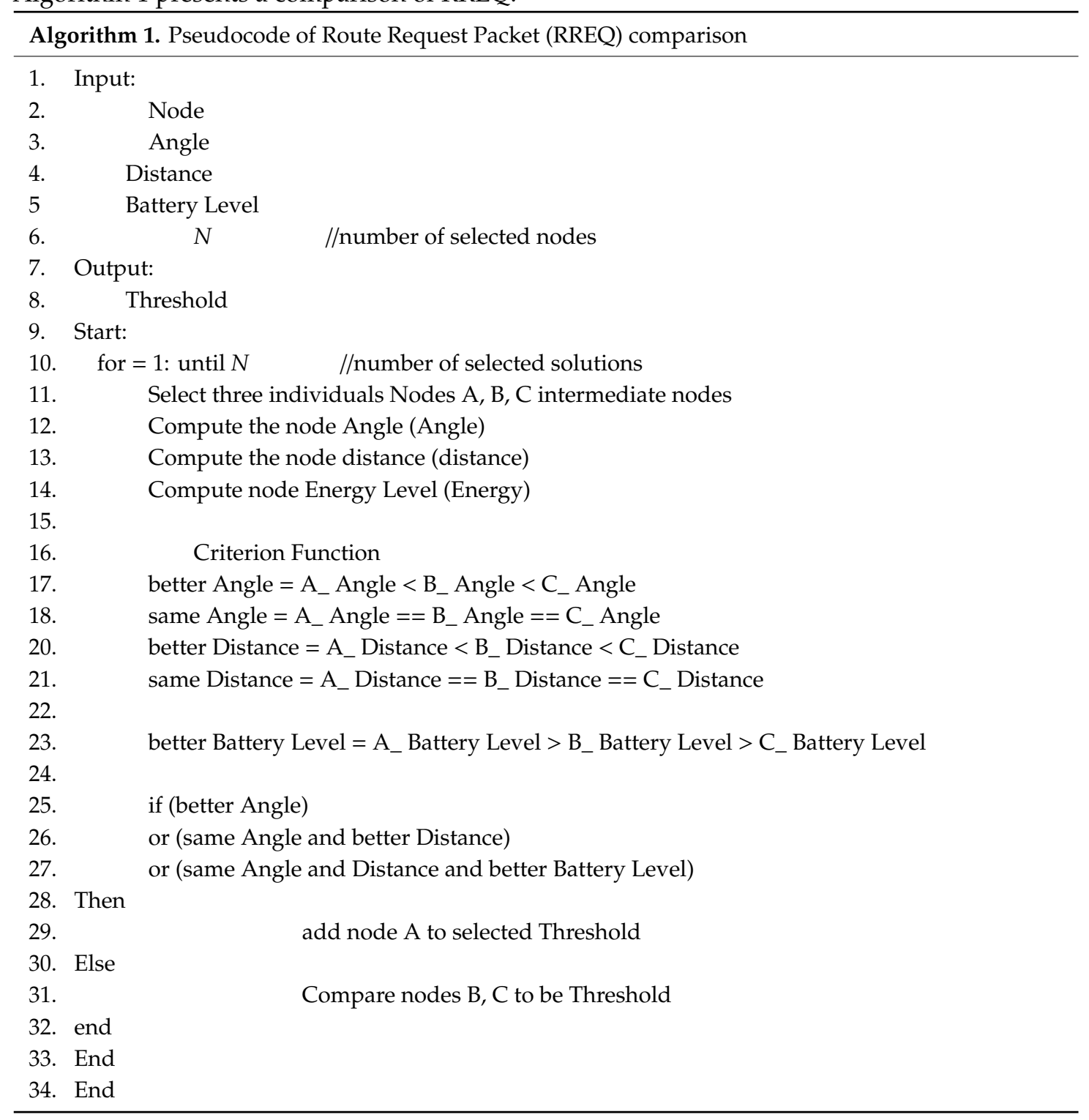

\subsection{Optimization Mechanism}

The optimization algorithm aids in searching the search space for the individual solutions to be fed into the LAR simulator for the generation of network measures. Then, the fitness values of the generated solution are calculated after feeding the solutions into the objective function. The calculation of the fitness values of the generated solutions and achieve the expected outcome, convenient values for the weights $\mathrm{w}_{1} \cdot \mathrm{w}_{2}$ and $\mathrm{w}_{3}$ must be chosen. Thus, the modified version of the PSO algorithm was 
selected for the basic PSO and mutation process (uniform). In addition, the FR has been included in the particle position. In addition, the coverage zone ratio (CZR) is a value $\in[0.1]$ that determines the coverage zone radius after being multiplied by the max coverage zone. The CZR is also included in the particle position by using Equation (7):

$$
F\left(n_{i}\right)=w_{1} \theta_{i}+w_{2} d_{i}+w_{3} e_{i}
$$

where $\theta$ is the angle of the subject node $i$ in consideration of the baseline between the source and destination; $d$ is the distance between $i$ and the destination; $e$ is the current energy of $i$, where $\mathrm{w}_{1} \cdot \mathrm{w}_{2}$ and $\mathrm{w}_{3}$ represent the weighting factors of the variables that are used in the objective function.

\section{Performance Metrics and Simulation Parameters}

The metrics considered in analyzing the performance of routing protocols are presented below.

Packet delivery ratio (PDR): The value of the division total number of the data packet is delivered into the total number of data packets transmitted by all nodes [42]. This metric is given by the following formula:

$$
\mathrm{PDR}=\frac{\sum \text { No of packets received }}{\sum \text { No of packets sent }} \times 100 \text {. }
$$

Overhead: The ratio of the RREQ packet number is calculated by dividing the number of RREQ packets with the sum of the number of packets sent and the number of RREQ packets [43] in the following equation:

$$
\text { RREQ Overhead }=\frac{\text { No of RREQs }}{\text { No of RREQs }+ \text { No of packets sent }} \times 100 .
$$

End-to-end delay (E2E): The data packet is based on the average time. The time of the transmission for the packet from the source is deduced based on the first delivered data packet to the destination [44], which is calculated as follows:

$$
\text { E2E Delay }=\frac{\sum \text { arrive time }- \text { send time }}{\sum \text { No of packets }} .
$$

Energy Consumption: This metric calculates the energy level of each node at the end of the simulation [44]. The value of energy consumption can be calculated using the following equation:

$$
\text { Energy Consumption }=\frac{\sum \text { Energy consumed in each node }}{\text { Initial energy }} \times 100 .
$$

Simulation Parameters: The simulation performed using MATLAB 2019b and the environment has been used to simulate the network based on $[23,25]$. Table 3 presents the simulation parameters of OPSO-LAR. 
Table 3. Simulation parameters

\begin{tabular}{|c|c|}
\hline \multicolumn{2}{|l|}{ Used Parameters } \\
\hline \multicolumn{2}{|c|}{ Network Parameters } \\
\hline Environment dimensions (width $\times$ height) & $1000 \mathrm{~m} * 1000 \mathrm{~m}$ \\
\hline Node velocity & $20 \mp 2.5[\mathrm{~m} /$ second $]$ \\
\hline Experiment Duration & $100 \mathrm{~s}$ \\
\hline Rate of Logging Data & $10 \mathrm{~s}$ \\
\hline Number of Nodes & 65 nodes \\
\hline Max CZR & $250 \mathrm{~m}$ \\
\hline Initial battery energy & 17,000 [unit] \\
\hline \multicolumn{2}{|l|}{ PSO Parameters } \\
\hline No. of iterations & 1000 \\
\hline No. of particles & 40 \\
\hline Lower boundary of the position of the particle & {$\left[\begin{array}{llllllllllllll}0 & 0 & 0 & 0 & 0.25\end{array}\right]$} \\
\hline Upper Bounds of particle's position & 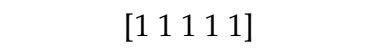 \\
\hline Lower Bounds of particle's velocity & {$[-0.5-0.5-0.5-0.2-0.2]$} \\
\hline Upper Bounds of particle's velocity & {$\left[\begin{array}{lllll}0.5 & 0.5 & 0.5 & 0.2 & 0.2\end{array}\right]$} \\
\hline Personal Acceleration Coefficient c1 & 2 \\
\hline Global Acceleration Coefficient c2 & 2 \\
\hline Inertia Coefficient w & 1 \\
\hline Damping Ratio of w & 0.99 \\
\hline Mutation Rate & 0.2 \\
\hline
\end{tabular}

\section{Evaluation Results and Discussions}

Evaluation results show that the proposed model outperforms the benchmark approaches $[23,25]$ in the same simulated network environment. For PDR, the results in both cases improve as the number of nodes is increased. However, given that the position of the nodes is continuously updated upon the successful addition of a new packet, the expected zone is usually small in most of the benchmark cases. This phenomenon prevents the response of the allowed zone to the requested packets. Hence, more data packets may not be sent to the benchmark, especially when the route to the destination node is a multi-hop path. Figure 4 shows the efficiency of OPSO-LAR and its progress relative to the other benchmark approaches. In comparison, we can easily see an improvement in the PDR when the number of nodes is 100 for the proposed model. 


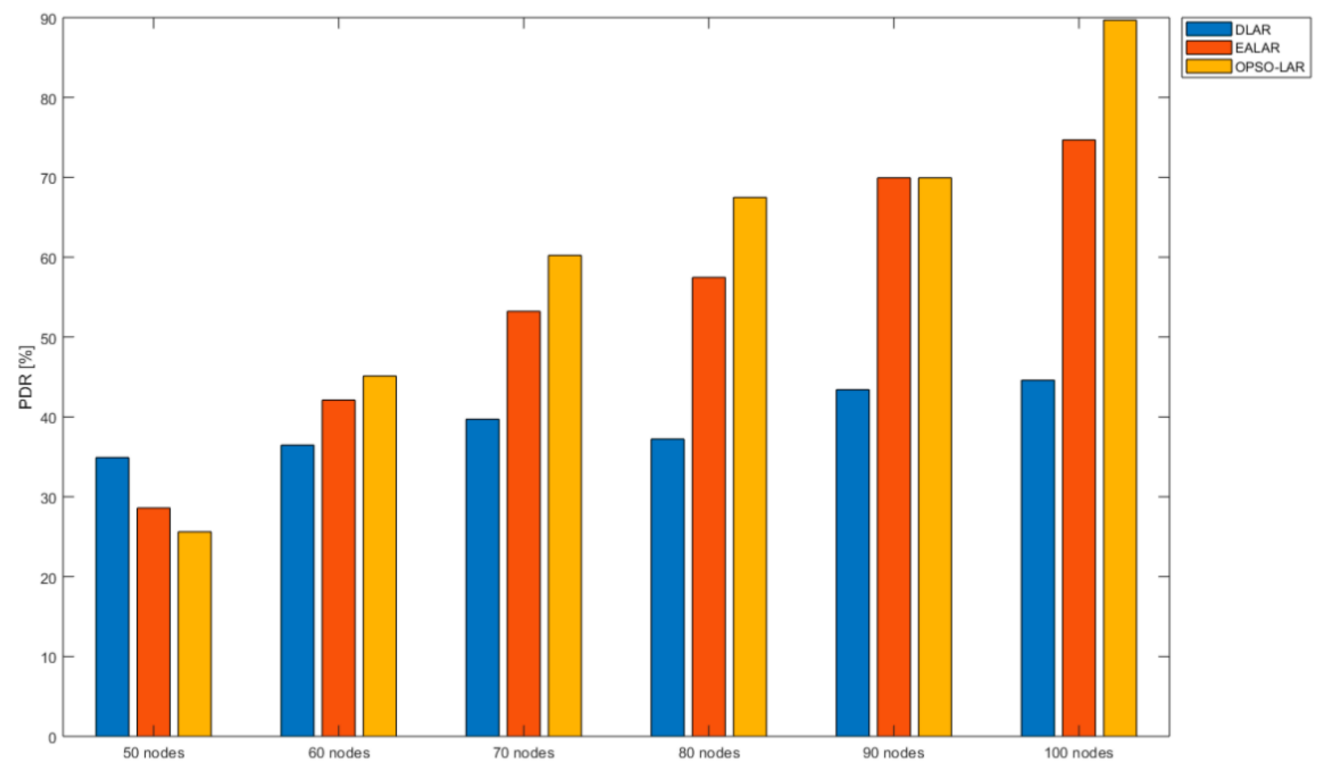

Figure 4. Packet delivery ratio of OPSO-LAR, Energy-Aware Location-Aided Routing (EALAR), and Density Aware Location-Aided Routing (DLAR).

A clear benefit of OPSO-LAR over EALAR and DLAR is observed via the measure for overhead. While OPSO-LAR can minimize the number of overhead packets, EALAR and DLAR fail to find the requested routing packet, which can be forwarded to its destination as a result of the narrow-allowed sending area, as shown in Figure 5.

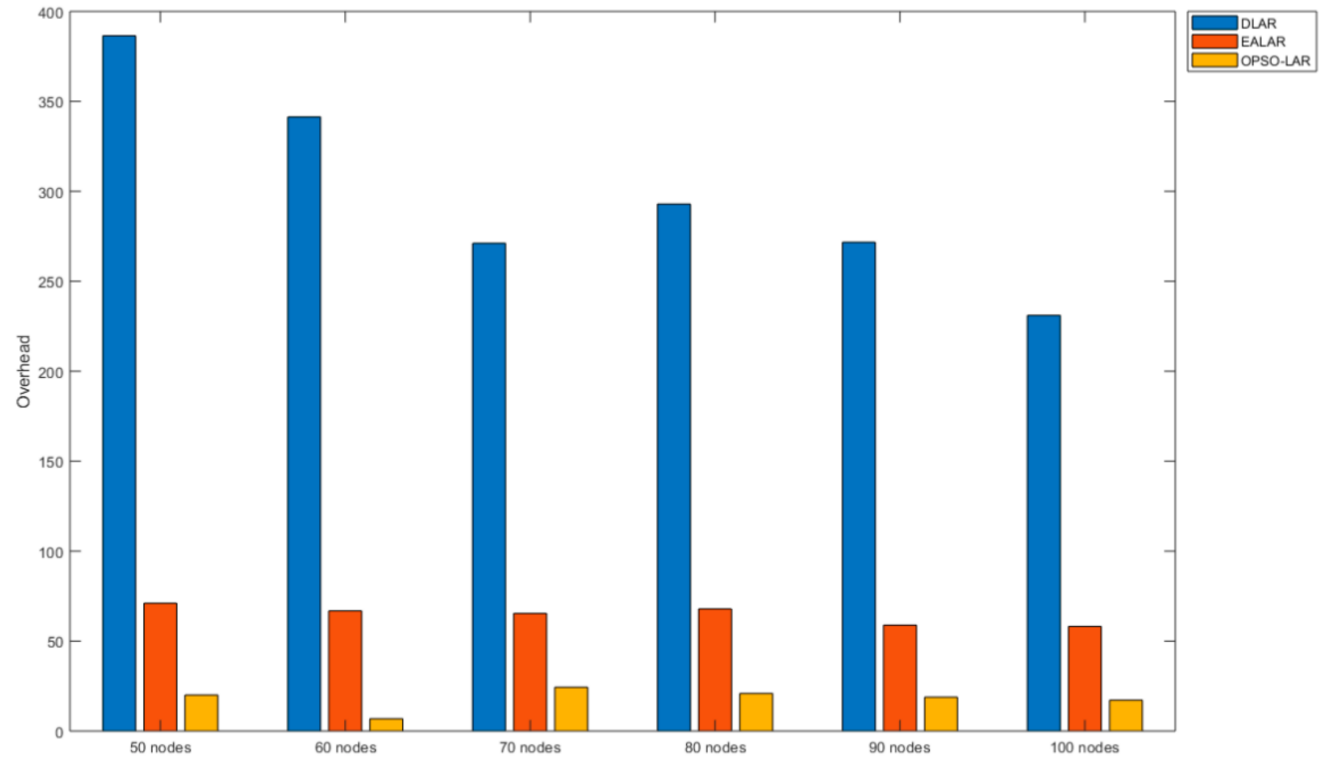

Figure 5. Overhead of OPSO-LAR, EALAR, and DLAR.

Regarding the E2E delay performance, the delay diminishes when the number of nodes is increased in both cases. However, our OPSO-LAR prolongs the delay during the sending of the packet to the destination because of the increase in speed and the number of hubs while the calculation of the packet delivers long E2E delay compared with EALAR and DLAR. Figure 6 displays the increase in OPSO-LAR. 


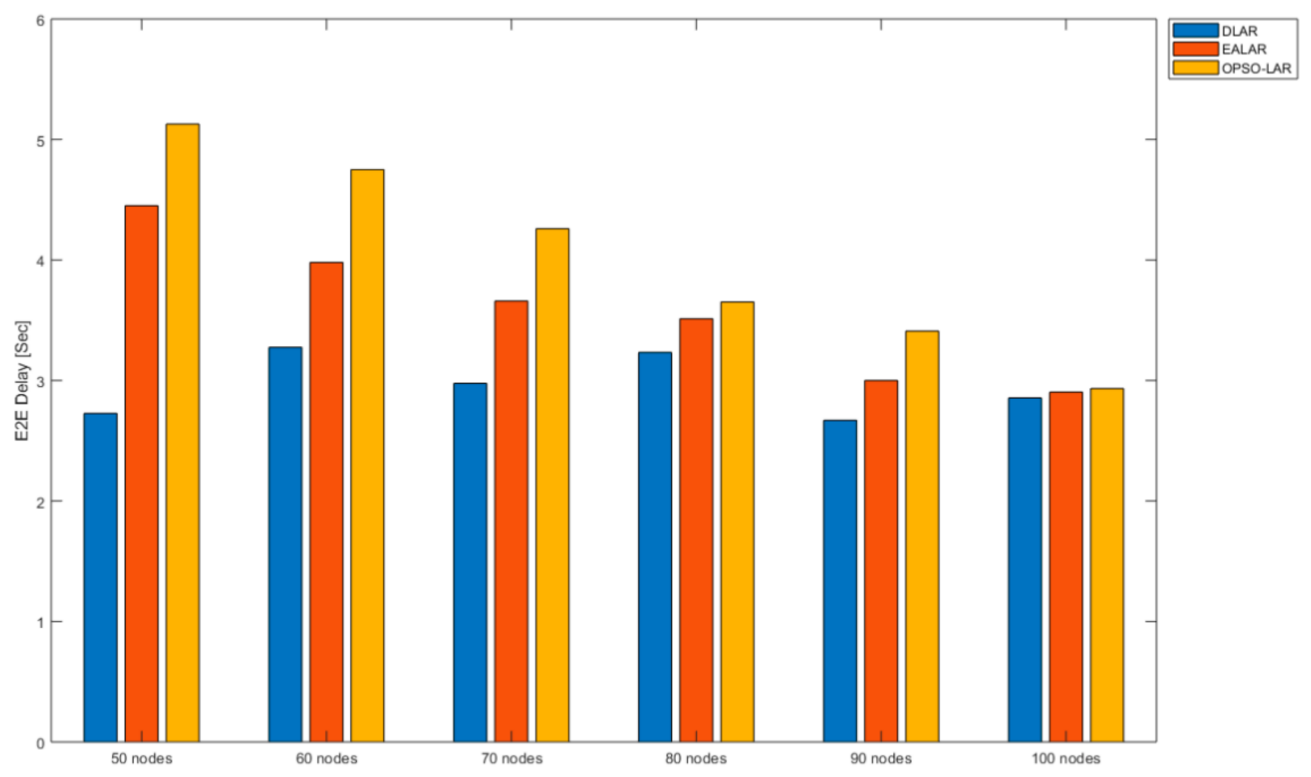

Figure 6. E2E delay of OPSO-LAR, EALAR, and DLAR.

The energy required to forward one packet is improved in OPSO-LAR compared with EALAR and DLAR. The energy wasted by sending several unnecessary routing requested packets (including control packets) without any significant improvement in the PDR.

Energy demand is clearly improved when the number of nodes in the network is 100, as shown in Figure 7. The figure shows the consumed energy per packet during the sending of the packets to the destination. Due to the initialization of the solution in the algorithm, the other approach achieves a higher accuracy than the proposed approach when the number of nodes is 50 . This result is identical to Figure 4 when the number of nodes is 50 nodes.

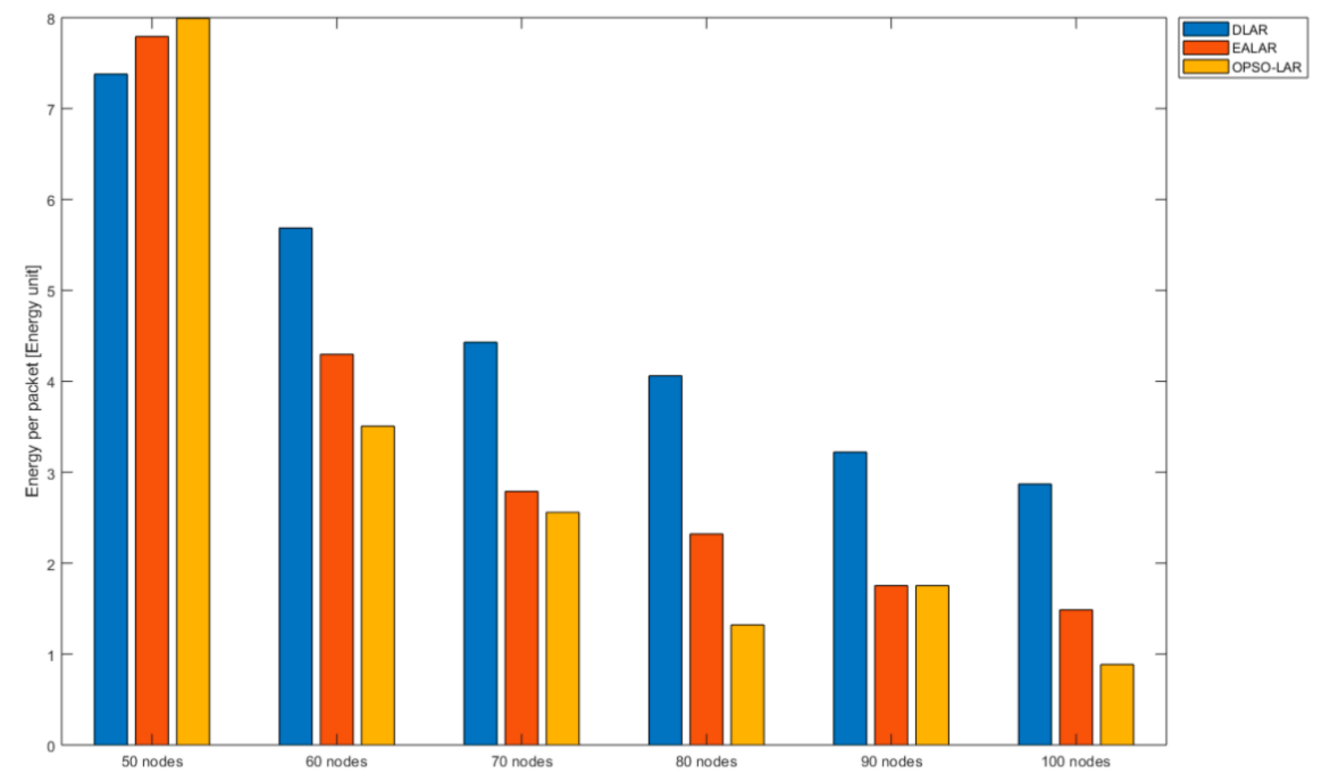

Figure 7. Energy per packet of OPSO-LAR, EALAR, and DLAR.

\section{Conclusions and Future Work}

The optimized conventional PSO was applied and integrated into the LAR protocol to minimize the required energy consumption. The evaluation results via simulation show that the proposed 
OPSO-LAR can achieve high performance compared with the relevant state of the artwork in a similar network environment. In specific, the PSO algorithm was employed for the parameter's optimization in the computation function. It was also used to select two or more parameters (FR \& CZR) that control network flooding and coverage of each node. For future work, we will add new features that enable the LAR protocol to avoid the E2E delay, which will improve the overall performance of the entire network, particularly energy consumption.

Author Contributions: Supervision, R.H. and R.C.M.; Validation, A.H.M.A.; Visualization, A.S.A.-K.; Writing — original draft, T.-A.N.A.; Writing-review \& editing, Q.N.N. All authors have read and agreed to the published version of the manuscript.

Funding: This paper is supported under grant Fundamental Research Grant Scheme FRGS/1/2018/TK04/UKM/02/07 and Dana Impak Perdana UKM DIP-2018-040.

Acknowledgments: The authors would like to acknowledge the support provided by the Network and Communication Technology (NCT) Research Groups, FTSM, UKM in providing facilities throughout this paper. The authors would also like to thank the Editor and the anonymous reviewers for their valuable comments and suggestions.

Conflicts of Interest: The authors declare no conflict of interest.

\section{References}

1. Liang, C.; Yu, F.R.; Zhang, X. Information-centric network function virtualization over 5G mobile wireless networks. IEEE Netw. 2015, 29, 68-74. [CrossRef]

2. Dupak, L.; Banerjee, S. Role of Bio-Inspired Algorithms for Designing Protocols in MANET-Review. In Proceedings of the 2019 International Carnahan Conference on Security Technology (ICCST), Chennai, India, 1-3 October 2019; pp. 1-6.

3. Zhu, L.; Liu, W.; Zhang, Z. Delay differential equations modeling of rumor propagation in both homogeneous and heterogeneous networks with a forced silence function. Appl. Math. Comput. 2020, 370, 124925. [CrossRef]

4. Ramya, P.; Gopalakrishnan, V. Proficient algorithms for enhancing topology control for dynamic clusters in MANET. Clust. Comput. 2019, 22, 9715-9726. [CrossRef]

5. Chen, Z.; Zhou, W.; Wu, S.; Cheng, L. An Adaptive on-Demand Multipath Routing Protocol With QoS Support for High-Speed MANET. IEEE Access 2020, 8, 44760-44773. [CrossRef]

6. Garaaghaji, A.; Alfi, A. A Fuzzy-Hierarchical Routing Algorithm for MANET Networks Allocation Rates Problem. Iran. J. Sci. Technol. Trans. Electr. Eng. 2019, 44, 1-9. [CrossRef]

7. AL-Dhief, F.T.; Sabri, N.; Fouad, S.; Latiff, N.A.; Albader, M.A.A. A review of forest fire surveillance technologies: Mobile ad-hoc network routing protocols perspective. J. King Saud Univ. Comput. Inf. Sci. 2019, 31, 135-146. [CrossRef]

8. Sumathi, K.; Priyadharshini, A. Energy optimization in manets using on-demand routing protocol. Procedia Comput. Sci. 2015, 47, 460-470. [CrossRef]

9. Mohseni, S.; Hassan, R.; Patel, A.; Razali, R. Comparative review study of reactive and proactive routing protocols in MANETs. In Proceedings of the 4th IEEE International Conference on Digital Ecosystems and Technologies, Dubai, UAE, 13-16 April 2010; pp. 304-309.

10. Muhammad, H.A.; Yahiya, T.A.; Al-Salihi, N. Comparative Study Between Reactive and Proactive Protocols of (MANET) in Terms of Power Consumption and Quality of Service. In Proceedings of the International Conference on Computer Networks, Kamień Ślaski, Poland, 25-27 June 2019; pp. 99-111.

11. Sharma, A.K.; Trivedi, M.C. Performance comparison of AODV, ZRP and AODVDR routing protocols in MANET. In Proceedings of the 2016 Second International Conference on Computational Intelligence \& Communication Technology (CICT), Ghaziabad, India, 12-13 February 2016; pp. 231-236.

12. Ko, Y.B.; Vaidya, N.H. Location-Aided Routing (LAR) in mobile ad hoc networks. Wirel. Netw. 2000, 6, 307-321. [CrossRef]

13. Alani, S.; Zakaria, Z.; Hamdi, M. A Study Review on Mobile Ad-Hoc Network: Characteristics, Applications, Challenges and Routing Protocols Classification Microwave Research Group (MRG), Centre for Telecommunication Research. Int. J. Adv. Sci. Technol. 2019, 28, 394-405. 
14. Mauve, M.; Widmer, J.; Hartenstein, H. A survey on position-based routing in mobile ad hoc networks. IEEE Netw. 2001, 15, 30-39. [CrossRef]

15. AL-Dhief, F.T.; Muniyandi, R.C.; Sabri, N. Performance evaluation of LAR and OLSR routing protocols in forest fire detection using mobile ad-hoc network. Indian J. Sci. Technol. 2016, 9, 48. [CrossRef]

16. Al-Dhief, F.T.; Latiff, N.M.A.; Malik, N.N.N.A.; Sabri, N.; Albadr, M.A.A.; Jawad, M.M. Power Consumption Efficient Routing Protocol for Forest Fire Detection based on Mobile Sensor Networks. In Proceedings of the 2019 IEEE 14th Malaysia International Conference on Communication (MICC), Selangor, Malaysia, 2-4 December 2019; pp. 7-12.

17. AL-Dhief, F.T.; Sabri, N.; Salim, M.; Fouad, S.; Aljunid, S. MANET routing protocols evaluation: AODV, DSR and DSDV perspective. In Proceedings of the MATEC Web of Conferences, Penang, Malaysia, 6-7 December 2017; p. 06024.

18. Mishra, A.; Singh, S.; Tripathi, A.K. Comparison of MANET routing protocols. Int. J. Comput. Sci. Mob. Comput. 2019, 8, 67-74.

19. Phoummavong, P.; Utsu, K.; Chow, C.O.; Ishii, H. Location-aided route discovery mechanism based on two-hop neighbor information for ad hoc network. J. Supercomput. 2016, 72, 1201-1214. [CrossRef]

20. Noguchi, T.; Kobayashi, T. Adaptive location-aware routing with directional antennas in mobile adhoc networks. In Proceedings of the 2017 International Conference on Computing, Networking and Communications (ICNC), Santa Clara, CA, USA, 26-29 January 2017; pp. 1006-1011.

21. Muniyandi, R.C.; Qamar, F.; Jasim, A.N. Genetic Optimized Location Aided Routing Protocol for VANET Based on Rectangular Estimation of Position. Appl. Sci. 2020, 10, 5759. [CrossRef]

22. Choudhary, R.; Sharma, P.K. An Efficient Approach for Power Aware Routing Protocol for MANETs Using Genetic Algorithm. In Emerging Trends in Expert Applications and Security; Springer: Cham, Switzerland, 2019; pp. 133-138.

23. Abdali, A.; Muniyandi, R.C. Optimized Model for Energy Aware Location Aided Routing Protocol in MANET. Int. J. Appl. Eng. Res. 2017, 12, 4631-4637.

24. Dubey, I.; Gupta, M. Uniform mutation and SPV rule based optimized PSO algorithm for TSP problem. In Proceedings of the 2017 4th International Conference on Electronics and Communication Systems (ICECS), Coimbatore, India, 24-25 February 2017; pp. 168-172.

25. Huang, S.C.; Chang, H.Y. A density-aware location-aided routing protocol for wireless ad-hoc networks. In Proceedings of the 2014 Tenth International Conference on Intelligent Information Hiding and Multimedia Signal Processing, Kitakyushu, Japan, 27-29 August 2014; pp. 670-673.

26. Goswami, S.; Agrawal, C.; Jain, A. Location based Energy Efficient Scheme for Maximizing Routing Capability of AODV Protocol in MANET. Int. J. Wirel. Microw. Technol. 2015, 5, 33. [CrossRef]

27. Gupta, N.; Gupta, R. LAR-1: Affirmative influences on energy-conservation and network lifetime in MANET. Int. J. Comput. Commun. Control 2014, 9, 284-291. [CrossRef]

28. Minh, T.P.T.; Nguyen, T.T.; Kim, D.-S. Location aided zone routing protocol in mobile Ad Hoc Networks. In Proceedings of the 2015 IEEE 20th Conference on Emerging Technologies \& Factory Automation (ETFA), Luxembourg, 8-11 September 2015; pp. 1-4.

29. Singh, K.; Sharma, A.; Singh, N.K. Linear regression based energy aware location-aided routing protocol for mobile ad-hoc networks. In Proceedings of the 2015 International Conference on Computational Intelligence and Communication Networks (CICN), Jabalpur, India, 12-14 December 2015; pp. 114-121.

30. Zhang, W.; Li, J.; Wang, X. Cost-efficient QoS routing protocol for mobile ad hoc networks. In Proceedings of the 19th International Conference on Advanced Information Networking and Applications (AINA'05) Volume 1 (AINA Papers), Taipei, Taiwan, 28-30 March 2005; pp. 13-16.

31. Zhang, D.-G.; Cui, Y.-G.; Zhang, T. New quantum-genetic based OLSR protocol (QG-OLSR) for Mobile Ad hoc Network. Appl. Soft Comput. 2019, 80, 285-296. [CrossRef]

32. Chaudhary, R.; Maduskar, D.; Tapaswi, S. Optimization based QoS aware routing algorithm in MANET. In Proceedings of the 2017 3rd International Conference on Advances in Computing, Communication \& Automation (ICACCA)(Fall), Dehradun, India, 15-16 September 2017; pp. 1-7.

33. Vikhar, P.A. Evolutionary algorithms: A critical review and its future prospects. In Proceedings of the 2016 International Conference on Global Trends in Signal Processing, Information Computing and Communication (ICGTSPICC), Jalgaon, India, 22-24 December 2016; pp. 261-265. 
34. Borwein, J.M.; Borwein, P.B. Pi and the AGM: A study in analytic number theory and computational complexity. Bull. Am. Math. Soc. 1990, 22, 198-201.

35. Chaudhry, R.; Tapaswi, S.; Kumar, N. Forwarding Zone enabled PSO routing with Network lifetime maximization in MANET. Appl. Intell. 2018, 48, 3053-3080. [CrossRef]

36. Kennedy, J.; Eberhart, R. Particle swarm optimization. In Proceedings of the ICNN'95-International Conference on Neural Networks, Perth, Australia, 27 November-1 December 1995; pp. 1942-1948.

37. Rathi, P.S.; Rao, C.M. Survey Paper on Routing in MANETs for Optimal Route Selection Based on Routing Protocol with Particle Swarm Optimization and Different Ant Colony Optimization Protocol. In Smart Intelligent Computing and Applications; Springer: Cham, Switzerland, 2020; pp. 539-547.

38. Sindhuja, S.; Vadivel, R. Extensible Particle Swarm Optimization Technique Using Route Set Choosing Algorithm in MANET. In Proceedings of the 2020 International Conference on Emerging Trends in Information Technology and Engineering (ic-ETITE), Vellore, India, 24-25 February 2020; pp. 1-8.

39. Mandhare, V.; Thool, V.; Manthalkar, R. QoS Routing enhancement using metaheuristic approach in mobile ad-hoc network. Comput. Netw. 2016, 110, 180-191. [CrossRef]

40. Chatterjee, S.; Das, S. Ant colony optimization based enhanced dynamic source routing algorithm for mobile Ad-hoc network. Inf. Sci. 2015, 295, 67-90. [CrossRef]

41. Nabil, M.; Hajami, A.; Haqiq, A. Improvement of location aided routing protocol in Vehicular Ad Hoc Networks on highway. In Proceedings of the 2015 th World Congress on Information and Communication Technologies (WICT), Marrakech, Morocco, 14-16 December 2015; pp. 53-58.

42. Tuteja, A.; Gujral, R.; Thalia, S. Comparative performance analysis of DSDV, AODV and DSR routing protocols in MANET using NS2. In Proceedings of the 2010 International Conference on Advances in Computer Engineering, Bangalore, India, 20-21 June 2010; pp. 330-333.

43. Jubair, M.A.; Mostafa, S.A.; Muniyandi, R.C.; Mahdin, H.; Mustapha, A.; Hassan, M.H.; Mahmoud, M.A.; Al-Jawhar, Y.A.; Al-Khaleefa, A.S.; Mahmood, A.J. Bat Optimized Link State Routing Protocol for Energy-Aware Mobile Ad-Hoc Networks. Symmetry 2019, 11, 1409. [CrossRef]

44. Thaseen, I.S.; Santhi, K. Performance analysis of FSR, LAR and ZRP routing protocols in MANET. Int. J. Comput. Appl. 2012, 41, 20-24.

Publisher's Note: MDPI stays neutral with regard to jurisdictional claims in published maps and institutional affiliations.

(C) 2020 by the authors. Licensee MDPI, Basel, Switzerland. This article is an open access article distributed under the terms and conditions of the Creative Commons Attribution (CC BY) license (http://creativecommons.org/licenses/by/4.0/). 